\title{
Uma mirada social sobre a história da psicologia
}

\section{A social approach to the History of Psychology}

\author{
Rodolfo Luís Leite Batista \\ Universidade Federal de Minas Gerais \\ Centro Universitário Presidente Tancredo de Almeida Neves \\ Brasil
}

\begin{abstract}
Portugal, F. T., Facchinetti, C. \& Castro, A. C. (Org.s.). (2018). História social da psicologia. Rio de Janeiro: Nau.
\end{abstract}

A produção brasileira em História da Psicologia tem se tornado cada vez mais diversificada, fato que se manifesta na multiplicidade de temas investigados, na existência de grupos de pesquisa consolidados em instituições públicas e privadas, na criação de sociedades científicas, na realização de eventos e na publicação de livros, coletâneas e dossiês temáticos em periódicos acadêmicos. Essas iniciativas mostram que a História da Psicologia (ou melhor, as histórias das psicologias, propositalmente no plural) permite compreender contextualmente as práticas psicológicas e conhecer seus compromissos ético-políticos em diferentes temporalidades - inclusive neste tempo presente. Nesse cenário de desenvolvimento teórico, faz-se necessária a divulgação de obras que introduzam estudantes e pesquisadores nos debates acerca da historicidade dos campos psi, bem como os auxiliem a se posicionar adequadamente nessa eminente área da psicologia brasileira. Nessa esteira, vem a público o livro História Social da Psicologia, organizado por Francisco Teixeira Portugal, Cristiana Facchinetti e Alexandre de Carvalho Castro, pesquisadores ligados ao Grupo de Trabalho em História Social da Psicologia da Associação Nacional de Pesquisa e Pós-graduação em Psicologia.

A obra pretende "problematizar narrativas e procedimentos disseminados entre historiadores da psicologia" (Portugal, Facchinetti \& Castro, 2018, p. 8) em seis capítulos. $\mathrm{Na}$ primeira parte, composta de três capítulos assinados pelos organizadores do livro, discutem-se os motivos, as formas e alguns resultados de pesquisas nesse campo. Introduz-se, sem grandes pretensões normativas, o campo da História Social da Psicologia, caracterizando seus objetivos e métodos. Na segunda parte, apresentam-se estudos sobre temáticas sociais, que estão em estreito diálogo com a psicologia e sua história: a libertação, o racismo e a historiografia da Psicologia 
Social. Exemplifica-se o debate empreendido na primeira parte da obra por meio de pesquisas em história social sobre problemas contemporâneos e de suas marcas trazidas do passado.

O capítulo Por que fazer uma História Social da Psicologia? abre o livro com um questionamento frequentemente feito por estudantes no início de cursos de graduação e busca apresentar a abordagem social em História da Psicologia. Inicialmente, os autores convidam o leitor a metaforicamente visitar um museu e argumentam o papel desse dispositivo para analisar a construção social do conhecimento. Os museus permitem contatar diferentes modos de se fazer história, desde os mais celebratórios e monumentais até aqueles contextualizados e críticos. Nesse sentido, os autores propõem a História Social da Psicologia como uma maneira de "desarrumar os museus, desnaturalizar algumas ideias fixas e contestar os fatos consumados" (Portugal, Facchinetti \& Castro, 2018, p. 15), permitindo mostrar as transformações sofridas pela psicologia em diferentes cenários. Esse fazer historiográfico rompe com a concepção de que o conhecimento histórico seja algo exclusivo para pessoas eruditas e afastadas da realidade cotidiana. Portanto, torna-se imperativo relativizar pesquisas que apenas enaltecem certos personagens e instituições (como acontece em alguns estudos sobre os processos de institucionalização e as ditas origens científicas da psicologia, sobre a circulação e a recepção de teorias e práticas psicológicas e as supostas relações centro-periferia) em vez de refletirem sobre a produção coletiva do conhecimento psicológico. O capítulo se encerra com um chamado a investigações sobre a participação de personagens e instituições brasileiras na história da psicologia, pois essa ciência não se constituiu (e constitui) exclusivamente em países europeus ou norte-americanos como teimam em apresentar alguns manuais e livros-texto.

Os modos de se fazer história social da psicologia e as opções metodológicas realizadas pelos pesquisadores são debatidos no capítulo Ver a história na psicologia ou a psicologia na história?. Nele, articulam-se duas relações entre a psicologia e a história. De um lado, a primeira perspectiva enaltece a necessidade de se considerar as determinações históricas da psicologia, pois esse campo do conhecimento é um produto cultural. Os objetos, os métodos e as teorias psicológicas são formulados socialmente. Nesse sentido, compreensões a-históricas agem politicamente ao manterem o estatuto de cientificidade de pretensos fundadores da psicologia, por exemplo. De outro, a segunda relação destaca a importância de se perceber a presença da psicologia ao longo do tempo, identificando as marcas e os impactos ocasionados por ela. Nesse trecho, os autores também criticam a fragilidade das narrativas anacrônicas da história da psicologia (especialmente, da Psicologia Social) e mostram a importância de se fazer a crítica do processo de construção de verdades históricas descontextualizadas. Eles concluem o capítulo mostrando a amplitude da 
questão-título, deixando-a como ponto de reflexão para o leitor a partir dos elementos conceituais descritos.

Embora a obra resenhada se dedique à história da psicologia em sentido amplo, ela estreita seus laços com a Psicologia Social, o que se evidencia em História Social dos efeitos e práticas da psicologia. No capítulo, os autores descrevem três momentos da história dessa subárea e criticam a arbitrária distinção entre teoria e prática, mostrando como a consolidação desse campo esteve atrelada a problemas de âmbito aplicado. Em primeiro lugar, é narrado o surgimento da Psicologia Social na França com os trabalhos de Gustave Le Bon e Gabriel Tarde, são apresentados outros autores e os principais temas vigentes durante o século XIX. Em seguida, os autores remontam à institucionalização dessa área nos Estados Unidos e às diversas transformações sofridas ao longo da primeira metade do século passado, que levaram a uma crise teórico-empírica a partir da década de 1960. No Brasil, as críticas ao ideário positivista, somadas ao contexto da Ditadura Militar e ao processo de regulamentação da profissão de psicólogo, fizeram com que se ampliasse o número de temáticas e formas de atuação da Psicologia Social no Brasil - eis o terceiro momento. Os autores destacam os trabalhos realizados na Pontifícia Universidade Católica de São Paulo como fundamentais para a consolidação desse campo e como importante marca da diversificação de práticas e modelos de intervenção do psicólogo brasileiro. O percurso e os exemplos oferecidos esclarecem a construção de teorias em função dos problemas originados na realidade social e corroboram a relativização da separação entre teoria e prática psicológicas. A descrição dessa variedade de temáticas e modos de atuação fecham a primeira parte do livro e abrem espaço para discussões essenciais para a Psicologia Social no Brasil - e também para sua história.

Em Historicizar para libertar: a proposta da Psicologia da Libertação, Fernando Lacerda Jr. aponta a Psicologia da Libertação como alternativa à insuficiência das propostas divulgadas pelos manuais clássicos de Psicologia Social para se superar os problemas sociopolíticos contemporâneos. Para caracterizar esse projeto de psicologia originado na América Latina, o autor inicialmente apresenta aspectos biográficos e a trajetória intelectual de seu principal expoente, Ignácio Martín-Baró. No entanto, Lacerda Jr. se recusa a construir uma narrativa celebratória acerca do pioneiro, pelo contrário, ele o insere em um contexto de produção teórica mais amplo, que se formalizou nos anos 1980. Esse movimento de crítica à incapacidade do modelo objetivista para descrever, compreender e intervir em realidades adversas, já mencionado em outros capítulos da obra, resultou em uma psicologia social que abandonou a suposta neutralidade positivista e se posicionou claramente a favor da democracia e da justiça social. Desse modo, Lacerda Jr. mostra que as proposições da Psicologia da Libertação se caracterizavam como predominantemente psicossociais, 
visavam transformar o panorama latino-americano e se baseavam na análise histórica que Martín-Baró realizou da psicologia de seu tempo. Por fim, o autor avança ao propor a História Social da Psicologia como forma de promover a libertação da psicologia contemporânea mediante a avaliação de suas premissas teórico-práticas. Dessa maneira, o capítulo evidencia a atualidade da Psicologia da Libertação e a apresenta como estratégia essencial para transformação da história humana por meio da ciência psicológica.

Escrito por Hildeberto Vieira Martins, o quinto capítulo Psicologia, raça e racismo: breve análise de suas bases históricas descreve o processo de construção da "questão racial" como objeto de estudo da psicologia no Brasil. Para tanto, o autor estabelece quatro eixos de análise: o primeiro, que cobre das décadas finais do século XIX às primeiras do século XX, foi marcado pelos esforços de Nina Rodrigues e outros pensadores em propor o olhar científico sobre o "negro" em pesquisas etnológicas. Em seguida, Martins mostra como o estabelecimento dos primeiros cursos de Psicologia Social e a institucionalização de outras ciências sociais, entre os anos 1920 e 1930, conduziram as discussões acerca da questão racial para uma perspectiva positiva, alinhada às necessidades de modernização do país. Nesse sentido, os trabalhos de Virgínia Leone Bicudo, Aniela Meyer Ginsberg, Otto Klineberg e Dante Moreira Leite são referenciados como investigações representativas da produção psicológica brasileira até a década de 1960. O terceiro período se caracterizou pela autonomização profissional e crise da Psicologia Social, que resultaram em um amplo espectro de pesquisas: desde os estudos sobre "preconceito", influenciados pelo cognitivismo norte-americano, de Aroldo Rodrigues aos trabalhos sobre dilemas raciais da população feitos sob enfoque psicanalítico. O momento atual, cujo início Martins identifica na década de 1990, é marcado pela apropriação de pautas étnicoraciais, que tem possibilitado a implementação de ações afirmativas, e abrem caminho para a compreensão da identidade como constructo social. Esse capítulo ressalta o papel de temas como "raça" e "racismo" na organização social do país e na disciplinarização e profissionalização dos saberes psicológicos.

O último capítulo As diferentes concepções de História em Psicologia Social, assinado por Renato Sampaio, descreve diferentes maneiras de se narrar a história da Psicologia Social no Brasil e aprofunda o debate empreendido na primeira parte da obra. De início, Sampaio situa a historiografia positivista como o modelo sobre o qual recaem críticas originadas na Escola dos Annales (movimento também chamado de Nova História) e em matrizes inspiradas no pensamento de Karl Marx e de Michel Foucault. O referencial positivista, bastante difundido em manuais clássicos, constrói narrativas predominantemente factuais, centradas na figura de precursores e marcadas pelo encadeamento evolutivo do processo histórico. Embora fundamental 
para a institucionalização da área, a historiografia positivista viu sua definição de "documento" e sua concepção evolucionista de tempo serem gradativamente abandonadas em favor de investigações sobre os desvios e as rupturas ao longo das cronologias, o que tem multiplicado o número de histórias da Psicologia Social. Além disso, o autor registra que as contribuições marxianas - e também marxistas - se deram a partir da década de 1970, enquanto as foucaultianas aconteceram desde a década seguinte. Para finalizar seu texto, Sampaio convida o leitor a identificar os desdobramentos desse debate historiográfico no atual cenário acadêmico e pontua a importância de que novas respostas sejam pensadas para as principais questões que perpassam o trabalho do historiador da psicologia.

É justo afirmar que a obra cumpre seus objetivos de maneira bastante exitosa. Do ponto de vista argumentativo, a apresentação de situações cotidianas e as referências a produções culturais não-acadêmicas (como ditos populares, letras de música e enredos de filmes) feitas ao longo da obra inserem o leitor na problemática abordada de maneira leve, sem colocar em risco a precisão e rigor esperados em uma publicação acadêmica. Com efeito, o leitor é convencido da necessidade de se mirar a psicologia criticamente, compreendendo-a inserida em seu contexto, levando em consideração as escolhas teóricas realizadas pelo pesquisador que a toma como objeto de investigação.

É aconselhado que os capítulos sejam lidos tal como dispostos no sumário da edição, pois os autores fazem diversas remissões a questões discutidas em diferentes trechos da obra. Dessa forma, sugerem-se diferentes níveis de interpretação para História Social da Psicologia: os alunos de graduação e os novos entusiastas da área podem lê-la como uma introdução aos estudos históricos da psicologia em perspectiva social; os estudantes de pós-graduação, docentes e pesquisadores mais experimentados nela encontrarão reflexões sobre importantes debates historiográficos - como as relações entre internalismo e externalismo ou continuísmo e descontinuísmo, os mitos criados sobre a institucionalização científica e a controversa função narrativa dos pioneiros da psicologia. Essas leituras permitem depreender que os olhares apresentados ao longo dos capítulos se voltam para o estudo do passado do mais longínquo ao mais recente - das psicologias não como um enfadonho passeio por um museu de antiguidades empoeiradas, mas como uma aventura que auxilia a entender melhor o presente. Entretanto, lamenta-se a ausência de um capítulo dedicado exclusivamente ao trabalho em centros de documentação, arquivos e acervos para a coleta de documentos e às formas de tratamento a serem dadas a essas fontes, pois, em alguns trechos da obra, o leitor fica pouco situado sobre o cotidiano da investigação histórica e alguns comentários nesse sentido poderiam elucidá-la. Finalmente, essa nova produção organizada por Portugal, Facchinetti e 
Castro vem se somar às publicações recentes sobre tendências historiográficas contemporâneas, ampliando caminhos para o estudo da História da Psicologia e se colocando como importante recurso para o ensino e a pesquisa nessa área em nosso país.

\section{Referência}

Portugal, F. T., Facchinetti, C. \& Castro, A. C. (Org.s.). (2018). História social da psicologia. Rio de Janeiro: Nau.

\section{Nota sobre o autor}

Rodolfo Luís Leite Batista é psicólogo e mestre em psicologia pela Universidade Federal de São João del-Rei. Atualmente, é doutorando pela Faculdade de Educação da Universidade Federal de Minas Gerais e professor-assistente no Centro Universitário Presidente Tancredo de Almeida Neves. Tem experiência nas áreas: História da Psicologia, Psicologia da Educação e Psicologia Fenomenológico-Existencial. E-mail: rodolforllb@gmail.com 